\title{
Editorial
}

\section{Funktionelle Lebensmittel: warum, was und wozu?}

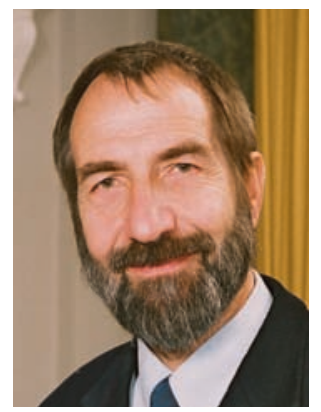

Die neue Bundesregierung setzt auf den kundigen, mündigen Verbraucher. Ein politisches Ziel ist es, den Konsumenten zu informieren und zu bilden, damit er aus der überbordenden Fülle des Angebots eine bewusste, nämlich die für ihn optimale Auswahl treffen kann.

Was aber heißt „optimal“? Bei einem großen Teil der Bevölkerung Deutschlands steht das Entscheidungskriterium „gesundheitsfördernd“ an oberer Stelle. Ist dem Einzelnen aber immer bekannt, welche Lebensmittel seiner Gesundheit zuträglich sind und welche er besser meiden sollte? Und woher bezieht er jene Kenntnisse, die ihn zu einer zielgerichteten Auswahl befähigen?

Viele Konsumenten entscheiden sich erst unmittelbar vor dem Verkaufsregal für das eine und gegen das andere Lebensmittel. Dabei lassen sie sich wesentlich von dem auf der Verpackung abgedruckten Text leiten. Kein Wunder also, dass die Industrie dort knackige, unmittelbar einleuchtende Botschaften platziert. Bei der Information zu den gesundheitlichen Wirkungen sind ihr die Hände gebunden. Verschiedene Regelwerke schreiben EUweit vor, welche Aussagen zu Gesundheitsförderung und Krankheitsprävention erlaubt sind.

Dies gilt auch und vor allem für solche Lebensmittel, die gerade mit dem Ziel eines gesundheitlichen Zusatznutzens komponiert worden sind. Unter den Bezeichnungen „Functional Food“ und „Funktionelle Lebensmittel“ erobern sie seit etwa 20 Jahren den Lebensmittelmarkt. Ihre Rezeptur zeichnet sich durch Anreicherungen, mitunter auch Abreicherungen von Nährstoffen oder durch Supplementierung mit sekundären Pflanzenmetaboliten, Ballaststoffen, Bakterien aus. Die Palette des Angebots ist mittlerweile breit. Das vorliegende Heft verschafft einen gedrängten Überblick zu den wesentlichen Produktgruppen.

Vermögen funktionelle Lebensmittel die an sie gerichteten Hoffnungen zu erfüllen? Dies können nur fundierte Studienergebnisse beantworten. So schreiben es auch die gesetzlichen Regelungen vor. Sie wenden sich eindeutig gegen jede Täuschung des Verbrauchers. Gegenwärtig fällt das wissenschaftliche Urteil über den Sinn und Nutzen von Functional Food eher kritisch aus. Noch sind zu wenige der angenommenen Effekte zweifelsfrei bestätigt. Klar ist aber, dass weiterführende Forschung lohnt. Bessere Kenntnis erhöht die Chance, den Gesundheitszustand der Bevölkerung durch Ernährungsstrategien zu verbessern. Dies ist nicht allein ein politisches, sondern ein ethisches Ziel.

Prof. Dr. Hans-Joachim F. Zunft 